\section{REFERENCES}

1. Bordeaux S, Harrison J. Injury and mortality in Australia. Australian Injury and Prevention Bulletin. Adelaide: National Injury Surveillance Unit, Flinders University, 1998.

2. Ozanne-Smith J, Watson W. A review of product-related fires. Melbourne: Monash University Accident Research Centre, 1991.

3. Begg S, Jolly D, Ozanne-Smith J. Where there's smoke: An evaluation of the effect of domestic smoke alarms on selected house-fire related outcomes in South-Eastern Australia. Monash University Accident Research Centre, Melbourne, Victoria. Unpublished.
4. NSW Health Department. NSW Health Survey 1997 Data (Preliminary). Sydney: Epidemiology and Surveillance Branch, NSW Department of Health.

5. Australian Bureau of Statistics. Household Safety, NSW. Sydney: ABS Publication no. 4347.1, 1998, p 9. it

Reports on the Smoke alarms wake you up if there is a fire project can be obtained from the NSW Multicultural Health Communication Service by telephone on (02) 93828111 or by email on mhcs@sesahs.nsw.gov.au.

\title{
A NEW HEALTH RISK FOR CHILDREN?
}

\section{John James and Chris Williams \\ Hunter Public Health Unit}

This article reports the results of two surveys of supermarkets in the Hunter area to determine whether poisonous products or products labelled 'keep out of reach of children' were displayed for sale within the stores in a location accessible to children.

\section{BACKGROUND}

The first survey in 1994 followed an incident in which a 21-month-old child, riding in a supermarket trolley, was able to take a bottle of insecticidal dog wash from a shelf, remove the child-resistant lid, and drink a quantity of the contents of the bottle. Active constituents of the dog wash were $50 \mathrm{~g} / \mathrm{L}$ diazinon (organophosphate insecticide) and $69 \mathrm{~g} / \mathrm{L}$ solvent (liquid hydrocarbon). The child was admitted into intensive care at a local hospital because of this life-threatening poisoning incident.

The aim of the survey was to determine if poisonous products, or products labelled 'keep out of reach of children', were displayed for sale in retail outlets in locations easily accessed by young children.

\section{METHODS}

A sample of convenience of 16 supermarkets stores in the Lower Hunter area was selected. All major supermarket chains were included. For the purpose of this survey, it was considered that products stored less than one metre from the floor were accessible to young children, either walking within the aisles of the store or being pushed in a shopping trolley or pram. The location of products with label warnings such as 'poison' or 'keep out of reach of children' was noted in each store. The products surveyed were limited to the following categories:
- household cleaners and solvents (caustic substances, methylated spirits, disinfectants, household cleansers, stain removers)

- household pesticides (fly sprays, surface sprays, cockroach baits, rat poisons)

- gardening pesticides (snail baits, insecticide powders and sprays, fungicides, herbicides)

- veterinary products (dog wash, kennel wash, insecticide sprays, and veterinary medication).

Packages of all these products were examined to see if they were fitted with child-resistant lids, caps or enclosures. Where possible, child-resistant lids or caps were checked to see if they were properly engaged or operating as designed.

\section{RESULTS}

All stores surveyed had products labelled 'poison' or 'keep out of reach of children' on shelves less than one metre from the floor.

In the store where the poisoning incident that prompted this survey occurred, the screw-down plastic child-resistant locking lids on two out of five $200 \mathrm{~mL}$ bottles of diazinon (organophosphate) insecticidal dog wash were not engaged. This was the same product consumed by the child in the poisoning incident.

The survey demonstrated that all supermarkets had poisonous products or products labelled 'keep out of reach of children' displayed for sale in locations that were within easy reach of children. The survey also showed that not all products labelled 'keep out of reach of children' had child-resistent packaging and, in some instances, childresistant packaging was defective. In particular, poisons packaged in $250 \mathrm{~mL}$ metal containers with screw-down plastic child-resistent lids were faulty and would not engage. 
The findings of this first survey were communicated to the supermarket industry.

\section{SURVEY}

A follow-up survey of four supermarket stores (again including the main supermarket chains operating in the Hunter area) was conducted in June 1999 to see whether changes had been implemented. The same methodology was applied.

\section{Results}

All stores had products labelled 'poison' or 'keep out of reach of children' on shelves less than one metre from the floor.

As with the first survey, a problem was identified with poisons packaged in $250 \mathrm{~mL}$ metal containers fitted with screw-down plastic child-resistant locking lids. In the four stores resurveyed, the child-resistant locking lids on 48 per cent of these containers were not engaged. Poisons packaged in this type of container were organophosphate insecticides and paint stripper.

The second survey found 36 per cent of products labelled 'keep out of reach of children' were not presented in childresistant packaging.

\section{DISCUSSION}

The provisions of the NSW Poisons Act 1966 govern the listing and labelling of dangerous products. Under this Act, products designated as dangerous are required to show label warnings. The National Registration Authority based in Canberra registers product labelling and packaging of harmful substances. Some of the National Registration Authority inspectorial duties are delegated to various state departments of agriculture. In NSW, the State Department of Agriculture will investigate any specific incident relating to labelling or faulty packaging of scheduled poisonous products.

Only products labelled 'poison' are required by the Act to have child-resistant packaging. Safety packaging has had a dramatic effect on morbidity and mortality of accidental poisoning; ${ }^{1}$ however, packaging should not be relied upon as the sole means of reducing exposures. Studies have shown that children gained access to the potential toxin by opening a properly closed child-resistant package in 20 per cent of poisonings. ${ }^{2}$

Both the 1994 and 1999 surveys identified a number of deficiencies in child-resistant packaging. In this regard, a review of the Australian Standard for Child-Resistant Packaging could improve quality control and ensure that enclosures operate as designed and are properly engaged prior to release to retail outlets.
All of the supermarket stores surveyed displayed products labelled 'poison' or 'keep out of reach of children' within easy reach of young children. The label warning 'keep out of reach of children' is required by legislation to be on certain products because death or injury could occur if the contents were either ingested or inhaled, or if contact were made with the mucous membranes, eyes or skin. In both surveys, the label warning 'keep out of reach of children' was not heeded in supermarkets or self-service type stores. This may pose a potential health risk to young children. This risk is magnified when combined with an absence of or faulty child-resistant packaging.

Discussion with retail industry representatives revealed that the major barrier to placing poisons on higher shelves is that product placement was determined by marketing priorities rather than by public health issues. In addition, there were insufficient data available describing childhood poisoning incidents in retail stores to support the rearrangement of product lines to higher shelves.

While there have been isolated reports of childhood poisoning in retail outlets throughout Australia, current surveillance is unable to estimate the true burden of illness from such incidents. A paediatric hospital in Western Australia reported five separate presentations to the emergency department between 1997 and 1998 following child poisoning incidents at retail outlets (unpublished data provided by Kidsafe Child Accident Prevention Foundation of Australia, Western Australian Division, July 1994). Data provided by the Victorian Injury Surveillance System, Monash University Accident Research Centre, showed 12 presentations to three Victorian hospital emergency departments between 1989 and 1993 following child poisonings in retail outlets. Because data are collected only from participating hospital emergency departments, other cases are probably unidentified. A standard national surveillance system for childhood poisoning-including information describing the setting where the poisoning occurred, where the poison was stored, and the presence or failure of any child-resistant enclosure-could assemble a profile of these incidents.

There is no legislation that regulates the placement of harmful substances or poisons in retail outlets; however, shoppers or visitors to stores in NSW are protected in a general way under the provisions of the $N S W$ Occupational Health and Safety Act 1983, which is administered by NSW Workcover Authority. Employers are required under occupational health and safety legislation to provide a safe workplace for employees and visitors to the workplace. The NSW Workcover Authority will investigate a particular incident in any workplace and take appropriate action if there is a breach of the 
Occupational Health and Safety Act.

In the absence of specific legislation requiring products labelled 'poison' or 'keep out of reach of children' to be placed on higher shelves in retail outlets, stores do have a duty of care to protect the safety of visitors to their stores. In this regard, self-service type stores would minimise the risk of toxic exposure to children as well as mitigate their legal liability if the stores heeded the warning on the label and kept products out of reach of children.

\section{CONCLUSION}

These survey results highlight a need for standardisation of packaging of poisons or products labelled 'keep out of reach of children' as well as better quality control of childresistant packaging. The true burden of illness caused by childhood poisoning in retail premises may not be recognised because of the lack of specific surveillance data kept by Australian health authorities. However, accidental child poisoning injuries would be reduced if the label warning 'keep out of reach of children' was heeded in all settings.

\section{ACKNOWLEDGMENTS}

The authors wish to acknowledge the assistance of Dr Craig Dalton, Director, and Ms Lynette Oakes, Hunter Public Health Unit; the cooperation and advice from the Australian Institute of Supermarkets, NSW Workcover Authority, NSW Department of Fair Trading, NSW Department of Agriculture, National Registration Authority for Agriculture and Veterinary Chemicals; and data supplied from the Victorian Injury Surveillance System, Monash University Accident Research Centre and the Kidsafe Child Accident Prevention Foundation of Australia, Western Australia Division.

\section{REFERENCES}

1. Matilda $\mathrm{S}$, McIntire MD, Carol $\mathrm{R}$ et al. How effective is safety packaging? Clinical Toxicology 1996; 9(3): 419-425.

2. Lembersky RB, Nichols MH, King WD et al. Controversies in toxicology: effectiveness of child-resistant packaging or toxin procurement in young poisoning victims. Vet Human Toxicology 1996; 38(5).

\section{THE DELIVERY OF POISONS INFORMATION IN AUSTRALIA: NATIONAL MEETING JULY 30}

\section{Pam Albany}

\section{Principal Policy Officer}

Injury Prevention Policy Unit

A national meeting of pharmacists, toxicologists and representatives from the State departments of health and the Commonwealth Department of Health and Aged Care was held to examine the current ability of poisons information centres in Australia to deliver quality poisons information to clinicians and the public in a cost-effective manner.

The major objective of this meeting was to seek a national consensus on the best model for delivering poisons information services nation-wide, including providing professional toxicological advice and disaster response. This national model will need to consider potential significant increases to service usage caused by new labelling requirements and an increased capacity for response to disaster. The meeting sought agreement on the most appropriate mechanism to insure that funding arrangements are secure and responsive to changes in the demand for services.
It is anticipated that the report emanating from this national level planning for poisons services will be considered by the Australian Health Ministers Advisory Council (AHMAC). There was agreement on a preferred model for delivering those services. Other significant issues discussed included the need to ensure appropriate remuneration for clinical toxicologists participating in the service and formulating an identified body of work to be undertaken to ensure that the clinical reporting system delivers useful information to an agreed set of users. Adopting national standards for workforce development, and employment opportunities for poisons information centres and professional support staff, are also perceived as critical to ensuring the continuation of adequate levels of staffing for all poisons information services in Australia.

\footnotetext{
For further details or for information concerning the outcomes of this meeting, please contact Ms Pam Albany, Principal Policy Officer, Injury Prevention Policy Unit, NSW Department of Health, by telephone on (02) 93919679 , or by email at palba@doh.health.nsw.gov.au.
} 